\title{
INFLUÊNCIA DO TIPO DE BANDEJA NA PRODUÇÃO DE MUDAS E NO RENDIMENTO E QUALIDADE DE BULBOS DE CEBOLA DE DIFERENTES CULTIVARES EM CULTIVO SOB PALHADA
}

\author{
Influence of trays type on seedlings production and bulb yield and quality \\ in differents onion cultivars under no tillage system
}

\author{
Marie Yamamoto Reghin ${ }^{1}$, Rosana Fernandes Otto', \\ Carlos Felipe Stülp Jacoby², Jean Ricardo Olinik ${ }^{2}$
}

\begin{abstract}
RESUMO
A cebola (Allium cepa L.) é uma das hortaliças de maior destaque na Região Sul, a qual contribui nacionalmente com $71,8 \%$ da área cultivada. Desse total, o Paraná participa com apenas 8,6\% e com baixa produtividade (10,7 t/ha), necessitando melhorar a tecnologia utilizada, incorporarando novas técnicas para tornar-se competitivo. Nesse contexto, objetivou-se avaliar a produção de mudas de cebola em diferentes bandejas e o seu desempenho posterior no cultivo sob palhada. A produção das mudas foi feita sob ambiente protegido, com o delineamento de blocos casualizados e três repetições; os tratamentos foram arranjados em um esquema fatorial 4 x 3, sendo quatro cultivares (Mercedes, Bola Precoce, Crioula e Montana) e três tipos de bandejas de poliestireno expandido (128, 200 e 288 células). As mudas provenientes de bandejas de 128 células foram designadas de M1, de 200 células de M2 e as de 288 células, de M3. O substrato usado foi o Plantmax ${ }^{\circledR}$ e a semeadura foi realizada em 18/06/04. Aos 54 dias da semeadura, as mudas foram avaliadas para as características de altura da parte aérea, comprimento da raiz, massa fresca e seca da parte aérea e da raiz. No campo, as mudas foram transplantadas aos 55 dias da semeadura, no delineamento experimental de blocos casualizados com três repetições e com os seguintes tratamentos: Mercedes M1; Mercedes M2; Mercedes M3; Bola Precoce M1; Bola Precoce M2; Bola Precoce M3; Crioula M1; Crioula M2; Crioula M3; Montana M1; Montana M2 e Montana M3. A colheita foi realizada em diferentes datas de acordo com a maturação das plantas. Avaliou-se o rendimento de bulbos e a classificação em classes, de acordo com o diâmetro dos bulbos. Os diferentes tipos de bandejas (128, 200 e 288 células) promoveram desenvolvimento de mudas com tamanhos diferentes. A melhor qualidade foi obtida na bandeja de 128 células para todas as cultivares (Mercedes, Bola Precoce, Crioula e Montana), principalmente para as características de altura , massa fresca da parte aérea e comprimento de raiz. As mudas de todos os tratamentos tiveram expressivo desenvolvimento vegetativo, alto rendimento $\left(79,23 \mathrm{t} / 8000 \mathrm{~m}^{2}\right)$ e alta qualidade dos bulbos, tendo Mercedes e Bola Precoce (com mudas M1 eM2) e Crioula e Montana (com mudas M1, M2 e M3), apresentado percentuais acima de 75\% de seu rendimento com bulbos das classes $3 \mathrm{C}$ e 4 .
\end{abstract}

Termos para indexação: Allium cepa, tamanho da muda, bandejas de isopor, rendimento de bulbos.

\begin{abstract}
Onion crop (Allium cepa L.) is one of the important vegetable on South, with 71,8\% of the whole onion area in Brazil. From this total, Paraná State shows only $8,6 \%$ having low yield of 10,7 t/ha. Its necessary advance on the usual technology and new techniques to become competitive. This experiment aimed to evaluate seedlings production on differents trays and its performance on plant development, bulb yield and quality under no tillage system. Seedlings production were carrried on protected cultivation, with a experimental design of randomized block and three replications; the treatments followed a factorial scheme $4 \times 3$, being four cultivars (Mercedes, Bola Precoce, Crioula and Montana) and three polystyrene trays (128, 200 and 288 cells). Seedlings obtained from trays of 128 cells were named M1, and those one obtained from 200 (M2) and 288 (M3). The substrate was Plantmax ${ }^{\circledR}$ and seeds were sowed in June, $16^{\text {th }}$. At 54 days seedlings were avaluated on the characteristics of height of upper part and root, fresh and dry weight of up ground and root material. At the field trial, the seedlings were transplanted at 55 days using a experimental design with three replications and the following treatments: Mercedes M1; Mercedes M2; Mercedes M3; Bola Precoce M1; Bola Precoce M2; Bola Precoce M3; Crioula M1; Crioula M2; Crioula M3; Montana M1; Montana M2 and Montana M3. During plant development it was avaluated the lenght of upper part, leaves number and the neck diameter. The harvest was realized in differents data in according of plants maturation. Bulb yield were avaluated and graded by diameter into classes. The different trays (128, 200 and 288 cells) promoted the development of seedlings with different size. The best seedling quality was obtained from trays of 128 cells to all cultivars mainly on the characteristics of height of upper part, fresh weight of upper ground material and root lenght. The seedlings promoted expressive plant development, high yield $\left(79,23 \mathrm{t} .8000 \mathrm{~m}^{-2}\right)$ and bulb quality, having the cultivars Mercedes and Bola Precoce (with seedlings M1 and M2) and Crioula and Montana (with seedlings M1, M2 and M3), percentage higher than $75 \%$ of the yield in bulbs graded into classes $3 \mathrm{C}$ and 4.
\end{abstract}

Index terms: Allim cepa, seedling size, polystyrene tray, bulb yield.

(Recebido para publicação em 19 de abril de 2005 e aprovado em 7 de outubro de 2005) 1'Doutoras, Professoras Adjunto de Olericultura, Departamento de Fitotecnia e Fitossanidade/Universidade Estadual de Ponta Grossa - Av. Carlos
Cavalcanti, 4748 - 84.030-900 - Ponta Grossa, PR - freghin@convoy.com.br

${ }^{2}$ Bolsistas de IC/CNPq, acadêmicos do $4^{\circ}$ ano do curso de Agronomia/Universidade Estadual de Ponta Grossa - Ponta Grossa, PR. 


\section{INTRODUÇÃO}

No Brasil, a cebola é a terceira hortaliça de maior expressão econômica, depois da batata e do tomate. Destacam-se os seguintes Estados: Santa Catarina, Rio Grande do Sul, São Paulo, Paraná, Bahia, Pernambuco e Minas Gerais, responsáveis pela quase totalidade da produção nacional (BOEING, 2002).

No Paraná, a cebola se constitui numa das principais culturas de subsistência de grande número de pequenos produtores das regiões de Imbituva e Irati, tendo apresentado na safra 2001/2002, o correspondente à área cultivada de 1.040 ha em Irati (SEAB/DERAL, 2002). No entanto, tem sido observado que a falta de planejamento da safra e de informações técnicas sobre os diferentes sistemas de cultivo, a desuniformidade de plantas, o baixo nível de tecnologia, são alguns dos fatores que levam à baixa produtividade da cultura $\left(10,7 \mathrm{t}^{\mathrm{h}} \mathrm{ha}^{-1}\right)$ e baixa qualidade do produto.

A cultura da cebola pode ser estabelecida pela semeadura direta, por bulbinhos, por mudas produzidas em bandejas ou mudas de raízes nuas obtidas em sementeira (FONTES \& SILVA, 2002), havendo predominância desta última. Em cebola, o uso de bandejas tem sido testado em casos específicos e considerado vantajoso, como na produção de bulbinhos (CARDOSO \& COSTA, 1999) e na produção de mudas de cebola no verão (VINCENZO \& TESSARIOLI NETO, 2003).

O sucesso na produção de bulbos depende, entre outros aspectos, da qualidade da muda obtida na sementeira. No entanto, essa qualidade vem sendo afetada por vários fatores, como por exemplo, o tombamento e as doenças foliares (EPAGRI, 1995).

Tem sido observado pouca eficiência do processo convencional, de obtenção de mudas em sementeira, considerando que as sementes ficam expostas às condições muito desuniformes de solo, temperatura e umidade, conseqüentemente a germinação, a emergência e o crescimento das plântulas também são irregulares, com ocorrência de doenças e levando à obtenção de estandes falhos e desuniformes. A agilidade no processo, assim como a garantia de obtenção de mudas de qualidade é uma necessidade básica para obtenção de alto rendimento na cultura.

O método de cultivo que predomina no Estado do Paraná também é o da sementeira, sendo a semeadura realizada predominantemente em maio e junho, e com concentração do transplante de mudas no mês de agosto, tendo essas mudas mais de oitenta dias pós-semeadura. Esse período longo para obtenção da muda é decorrente principalmente de temperaturas baixas que predominam no período, além da ocorrência de geadas, o que têm contribuído para atrasar o desenvolvimento das mudas. Concomitantemente, para manter a alta sanidade das mudas nesse período, a intensidade de pulverização com defensivos na prática têm sido cada vez maior.

A utilização de bandejas de poliestireno expandido tem-se mostrado eficiente na produção, condução, transporte e transplantio das mudas de hortaliças para o local definitivo, já que as bandejas são leves, de fácil manuseio comportando um número muito grande de mudas, ocupando uma área mínima e permitindo o transplante de mudas com torrão (MINAMI, 1995).

O transplante de mudas de cebola produzidas em bandejas tornou-se o método mais eficiente na Holanda e Canadá, porque confere maior uniformidade da muda, evitando a competição entre plantas, observada usualmente na sementeira. Além disso, não há estresse nas raízes durante o transplante (JAIME et al., 2001).

$\mathrm{Na}$ Itália, quando se comparou três sistemas de propagação (semeadura direta, transplante de mudas provenientes de sementeira ou de bandejas de poliestireno expandido), o rendimento de bulbos foi maior quando as mudas foram produzidas em bandejas (DELLACECCA et al., 2000).

Na produção de mudas em bandejas, o tamanho da célula é um fator que influencia diretamente o desenvolvimento e a arquitetura do sistema radicular (LATIMER, 1991). Diferentes tamanhos de bandejas proporcionarão mudas com diferentes tamanhos para serem transplantadas.

$\mathrm{Na}$ Flórida, as mudas produzidas em volume de célula de $4,0 \mathrm{~cm}^{3}$ produziram $16 \%$ a menos de bulbos de maior padrão do que mudas oriundas de volume de $7,1 \mathrm{~cm}^{3}$ (LESKOVAR \& VAVRINA, 1999).

Com o presente trabalho, objetivou-se avaliar a influência de diferentes tipos de bandejas na produção de mudas de cebola (Allium cepa L.) e no desenvolvimento das plantas no campo, no rendimento e na qualidade dos bulbos das cultivares Mercedes, Bola Precoce, Crioula e Montana, em sistema de cultivo sob palhada.

\section{MATERIAL E MÉTODOS}

O experimento teve a etapa de produção de mudas conduzida no Viveiro Primavera, em Ponta Grossa (PR), sob cultivo protegido com estrutura metálica em arco coberto com filme de polietileno de 120 micras. O delineamento experimental foi o de blocos casualizados, com três repetições; os tratamentos foram distribuídos 
conforme fatorial 4 × 3, sendo quatro cultivares (Mercedes, Bola Precoce, Montana e Crioula) e três tipos de bandejas de poliestireno expandido com 128 células $\left(40 \mathrm{~cm}^{3}\right), 200$ (16 $\left.\mathrm{cm}^{3}\right)$ e 288 células $\left(10 \mathrm{~cm}^{3}\right)$. O substrato usado nas bandejas foi o Plantmax HT2, procedendo-se a semeadura no dia 18/ 06/04, com duas sementes por célula e posterior desbaste após a emergência, mantendo-se uma muda por célula. Após 30 dias da semeadura, as mudas receberam uma adubação complementar com kristasol (15-30-15) na dose de 1 g.L $\mathrm{L}^{-1} \mathrm{H}_{2} \mathrm{O}$. Aos 54 dias da semeadura, as mudas foram avaliadas para as características de: altura da parte aérea, massa fresca da parte aérea e comprimento da raiz (após lavagem sob água corrente para retirada do substrato e secagem sob papel toalha). A massa seca das partes avaliadas foi obtida após secagem em estufa de ventilação forçada regulada com temperatura de $60^{\circ} \mathrm{C}$. O experimento de campo foi conduzido na Fazenda-Escola da Universidade Estadual de Ponta Grossa (PR), localizada a $880 \mathrm{~m}$ de altitude, em solo do tipo CAMBISSOLO HÁPLICO Tb Distrófico, de textura argilosa. O delineamento experimental foi o de blocos casualizados, com três repetições, constando cada bloco de doze tratamentos: 1) Mercedes, com muda obtida da bandeja de 128 células; 2) Mercedes, com muda obtida da bandeja de 200 células; 3) Mercedes, com muda obtida da bandeja de 288 células; 4) Bola Precoce, com muda obtida da bandeja de 128 células; 5) Bola Precoce, com muda obtida da bandeja de 200 células; 6) Bola Precoce, com muda obtida da bandeja de 288 células; 7) Crioula, com muda obtida da bandeja de 128 células; 8) Crioula, com muda obtida da bandeja de 200 células; 9) Crioula, com muda obtida da bandeja de 288 células; 10) Montana, com muda obtida da bandeja de 128 células; 11) Montana, com muda obtida da bandeja de 200 células e 12) Montana, com muda obtida da bandeja de 288 células. As mudas obtidas nas bandejas de 128, 200 e 288 células foram denominadas de M1, M2 e M3, respectivamente. A área do experimento teve previamente a aveia dessecada, rolada e o preparo mínimo do solo constou de sulcamento manual das linhas a cada $0,40 \mathrm{~m} \mathrm{e}$ adubação nessas, utilizando a fórmula 5-25-25, na quantidade de $0,050 \mathrm{~kg} / \mathrm{m}$. O transplante foi realizado no dia 08/07/04, aos 54 dias da semeadura. Cada parcela constou de quatro fileiras com 2,0 m de comprimento cada uma, com as plantas arranjadas no espaçamento 0,40 x 0,08 $\mathrm{m}$. Aos 57 dias do transplante, nas duas linhas centrais de cada parcela, em sete plantas ao acaso, foram avaliadas as características de altura, número de folhas expandidas e diâmetro do pseudocaule. Nessa época, avaliou-se a precocidade, por meio do número de plantas que apresentavam bulbificação, em relação ao número total de plantas da parcela, sendo o resultado expresso em porcentagem. A cultura foi irrigada por aspersão. A adubação em cobertura foi realizada antes da bulbificação, com uréia na quantidade de $20 \mathrm{~g} \cdot \mathrm{m}^{-1}$. O controle de plantas daninhas foi realizado manualmente uma vez, no início do desenvolvimento vegetativo. Procedeu-se três aplicações, com intervalo de 10 dias, de Clorotalonil (1012 g i.a.ha- $\left.{ }^{-1}\right)+$ Metalaxyl (101 g i.a.ha-1) após o transplante, devido à incidência de mildio (Peronospora destructor). Antes de proceder a colheita, foram avaliadas o número total de plantas por parcela, de plantas com estalo e com florescimento prematuro. A colheita foi realizada de acordo com a maturação das plantas, em uma área útil de $0,5 \mathrm{~m}^{2}$ (1,0 $\mathrm{m}$ de comprimento e $0,5 \mathrm{~m}$ de largura) abrangendo as duas linhas centrais, num total de 32 plantas. As datas de colheita foram: 03/11/04 para Mercedes M1 e 11/11/04 para M2 e M3. Bola Precoce M1 aos 17/11/04 e aos 20/11/04 para M2 e M3. Os outros tratamentos (Crioula M1, M2 e M3 e Montana M1, M2 e M3 foram colhidos em 30/11/04. Após a cura dos bulbos por um período de 22 dias, fez-se a toalete e contagem do número de bulbos e respectiva massa nas devidas classes de acordo com o diâmetro transversal do bulbo. Seguiu-se a classificação do M.A. (portaria 529 de 18/03/95). Foram considerados: classes 1 (>15<35 mm), 2 (>35<50 mm), $3(>50<60 \mathrm{~mm}), 3 \mathrm{C}(>60<70$ $\mathrm{mm}), 4(>70<90 \mathrm{~mm})$ e $5(>90 \mathrm{~mm})$. Os dados foram submetidos à análise de variância e as médias comparadas pelo teste de Tukey no nível de 5\% de probabilidade.

\section{RESULTADOS E DISCUSSÃO}

As características de número de folhas, altura e massa fresca da parte aérea das mudas de cebola apresentaram comportamento dependente do tipo de bandeja e da cultivar (Tabela 1). O número de folhas não apresentou grandes variações em função do volume da célula, exceto para Bola Precoce e Montana. No entanto, quanto maior o volume da célula maior foi a altura e massa fresca da parte aérea (exceto para Mercedes que não diferiu entre as bandejas de 200 e 288 células). Entre cultivares, cabe o destaque para Mercedes, com os maiores valores tanto na altura como na massa fresca apresentada. Na bandeja de 128 células observou-se maior valor de altura $(30,93 \mathrm{~cm})$ o que demonstra que no maior volume de célula, maior é o tamanho da muda e mais rapidamente estará a muda apta para o transplante. Quanto ao número de folhas, Montana apresentou os maiores valores, tanto na bandeja de 128 como de 200 células. $\mathrm{Na}$ bandeja de 288 células, observou-se menor 
desenvolvimento de folhas, exceto na cultivar Mercedes. Outros autores também observaram que o volume maior da célula promove maior desenvolvimento da muda, tanto em cebola (LESKOVAR \& VAVRINA, 1999) como em outras hortaliças (BARROS, 1997; MODOLO \& TESSARIOLI NETO, 1998; REGHIN et al., 2004; RESENDE et al., 2003).

As demais características de comprimento e massa fresca da raiz, diâmetro do pseudocaule e massa seca da parte aérea e da raiz (Tabela 2), apresentaram os maiores valores na bandeja de 128 células (exceto no diâmetro do pseudocaule), não sendo observadas diferenças entre as bandejas de 200 e 288 células para massa fresca da raiz e massa seca da parte aérea. Entre cultivares, nas mesmas características, Mercedes confirmou maior desenvolvimento, com maior valor na massa seca da parte aérea. As características de raiz, embora tenham demonstrado diferença na massa fresca, tanto o comprimento como a massa seca demonstraram comportamento semelhante entre as cultivares ( Tabela 2).

TABELA 1 - Características de número de folhas, altura da parte aérea e massa fresca apresentadas pelas mudas das cultivares Mercedes, Bola Precoce, Montana e Crioula, em função do tipo da bandeja (B128=128 células; B200=200 células e B288=288 células). Ponta Grossa (PR). 2004.

\begin{tabular}{lcccccccccc}
\hline & \multicolumn{3}{c}{$\mathbf{N}^{\mathbf{0}}$ de folhas } & \multicolumn{3}{c}{ Altura $(\mathbf{c m})$} & \multicolumn{3}{c}{ Massa fresca (g/planta) } \\
\hline Cultivar & $\mathbf{B ~ 1 2 8}$ & B 200 & B 288 & B 128 & B 200 & B 288 & B 128 & B 200 & B 288 \\
\hline Mercedes & $3,0 \mathrm{Ab}$ & $3,0 \mathrm{Aa}$ & $3,0 \mathrm{Aa}$ & $30,93 \mathrm{Aa}$ & $24,86 \mathrm{~B} \mathrm{a}$ & $23,33 \mathrm{Ba}$ & $1,96 \mathrm{~A} \mathrm{a}$ & $1,10 \mathrm{Ba}$ & $1,06 \mathrm{Ba}$ \\
B. Precoce & $3,0 \mathrm{Ab}$ & $3,0 \mathrm{Aa}$ & $2,7 \mathrm{Bb}$ & $25,33 \mathrm{Ab}$ & $21,76 \mathrm{~B} \mathrm{~b}$ & $14,95 \mathrm{Cb}$ & $1,27 \mathrm{~A} \mathrm{c}$ & $0,77 \mathrm{Bb}$ & $0,47 \mathrm{Cb}$ \\
Crioula & $3,0 \mathrm{Ab}$ & $3,0 \mathrm{Aa}$ & $2,8 \mathrm{Aab}$ & $23,66 \mathrm{Ab}$ & $18,72 \mathrm{~B} \mathrm{c}$ & $15,96 \mathrm{Cb}$ & $1,31 \mathrm{~A} \mathrm{c}$ & $0,72 \mathrm{Bb}$ & $0,50 \mathrm{Cb}$ \\
Montana & $3,5 \mathrm{Aa}$ & $3,0 \mathrm{Ba}$ & $2,8 \mathrm{Bab}$ & $26,33 \mathrm{Ab}$ & $19,38 \mathrm{Bbc}$ & $15,72 \mathrm{Cb}$ & $1,57 \mathrm{~A} \mathrm{~b}$ & $0,73 \mathrm{Bb}$ & $0,52 \mathrm{Cb}$ \\
\hline
\end{tabular}

*Médias seguidas da mesma letra maiúscula na linha e minúscula na coluna, não diferem significativamente entre si no nível de $5 \%$ de probabilidade pelo teste de Tukey.

TABELA 2 - Características de comprimento e massa fresca da raiz, diâmetro do pseudocaule, massa seca da parte aérea e da raiz em função do tipo da bandeja (B128=128 células; $B 200=200$ células e B288=288 células) e das cultivares Mercedes, Bola Precoce, Montana e Crioula. Ponta Grossa (PR). 2004.

\begin{tabular}{|c|c|c|c|c|}
\hline Características & B 128 & \multicolumn{2}{|c|}{ B 200} & B 288 \\
\hline Comprimento da raiz $(\mathrm{cm})$ & $6,39 \mathrm{~A}$ & \multicolumn{2}{|c|}{$5,16 \mathrm{~B}$} & $4,05 \mathrm{C}$ \\
\hline Massa fresca da raiz (g) & $0,47 \mathrm{~A}$ & \multicolumn{2}{|c|}{$0,29 \mathrm{~B}$} & $0,26 \mathrm{~B}$ \\
\hline Diâmetro do pseudocaule (mm) & $5,07 \mathrm{~A}$ & \multicolumn{2}{|c|}{$4,74 \mathrm{~A}$} & $4,28 \mathrm{~B}$ \\
\hline Massa seca da parte aérea $(\mathrm{g})$ & $0,16 \mathrm{~A}$ & \multicolumn{2}{|c|}{$0,10 \mathrm{~B}$} & $0,03 \mathrm{~B}$ \\
\hline Massa seca da raiz (g) & $0,05 \mathrm{~A}$ & \multicolumn{2}{|c|}{$0,03 \mathrm{~B}$} & $0,03 \mathrm{~B}$ \\
\hline Características & Mercedes & Bola Precoce & Montana & Crioula \\
\hline Comprimento da raiz $(\mathrm{cm})$ & $5,53 \mathrm{~A}$ & $5,53 \mathrm{~A}$ & $4,86 \mathrm{~A}$ & $4,89 \mathrm{~A}$ \\
\hline Massa fresca da raiz $(\mathrm{g})$ & $0,34 \mathrm{AB}$ & $0,29 \mathrm{~B}$ & $0,34 \mathrm{AB}$ & $0,38 \mathrm{~A}$ \\
\hline Diâmetro do pseudocaule (mm) & $5,49 \mathrm{~A}$ & $4,57 \mathrm{~B}$ & $4,46 \mathrm{~B}$ & $4,28 \mathrm{~B}$ \\
\hline Massa seca da parte aérea (g) & $0,16 \mathrm{~A}$ & $0,09 \mathrm{~B}$ & $0,10 \mathrm{~B}$ & $0,09 \mathrm{~B}$ \\
\hline Massa seca da raiz (g) & $0,03 \mathrm{~A}$ & $0,03 \mathrm{~A}$ & $0,04 \mathrm{~A}$ & $0,03 \mathrm{~A}$ \\
\hline
\end{tabular}

* Médias seguidas da mesma letra maiúscula na linha não diferem significativamente entre si no nível de 5\% de probabilidade pelo teste de Tukey. 
Aos 57 dias do transplante, observou-se grande desenvolvimento das plantas, principalmente nos tratamentos M1, nas características de altura, número de folhas e diâmetro do pseudocaule (Tabela 3). Os maiores contrastes ocorreram entre os tratamentos M1, com os maiores valores e M3, com os menores valores, demonstrando que o tamanho maior da muda é um atributo que define sua melhor qualidade no estádio de muda e essa qualidade se refletiu durante o desenvolvimento da planta. Todos os tratamentos apresentaram expressivo desenvolvimento vegetativo, se considerarmos que a média de altura foi $64,12 \mathrm{~cm}$, do número de folhas 8,64 e 15,95 mm de diâmetro do pseudocaule. Outro fator que pode ter contribuído para o desenvolvimento vegetativo foi o cultivo feito na palha, a qual pela maior retenção de umidade do solo e pela menor variação térmica na temperatura do solo (AMADO et al., 1990) pode ser considerada mais favorável a esta cultura.

A precocidade de bulbificação aos 57 dias do transplante foi um grande diferencial entre as cultivares (Tabela 3). Mercedes M1 destacou-se entre todos os tratamentos, apresentando $89,41 \%$ de plantas com bulbificação, enquanto em M2 e em M3, os percentuais foram $64,09 \%$ e $59,33 \%$, respectivamente. Estes tratamentos diferiram dos demais. Bola Precoce apresentou comportamento intermediário, tendo $24,25 \%$ em M1, 16,32\% em M2 e 10,78\% de plantas com bulbificação em M3. Crioula e Montana foram as mais tardias, sem ocorrência de bulbificação no período.

A precocidade de bulbificação refletiu-se na maturação das plantas, sendo Mercedes a primeira cultivar colhida, tendo apresentado $83,7 \%, 90,8 \%$ e $95,4 \%$ de estalo, respectivamente, em mudas M1, M2 e M3 (Tabela 4). A porcentagem de estalo foi maior de M1 para M3, embora não tenha havido diferença significativa. Mesmo que a bulbificação tenha sido mais precoce em M1, quando comparada à M2 e M3, a maturação foi mais rápida em M3. Portanto, plantas menores, advindas de mudas menores (M3), apresentaram maturação mais rápida. Todos os tratamentos apresentaram alto percentual de estalo, o que é uma característica desejável, pois demonstra adaptabilidade da planta ao local, à época de cultivo e à técnica empregada. Brewster (1994) recomenda a colheita quando o campo apresentar entre 50 e $80 \%$ das plantas com o pescoço amolecido e quando a folhagem inicia o tombamento sobre o solo. Somente Crioula M1 foi colhida com porcentagem de estalo abaixo de $75 \%$, devido à ocorrência de florescimento prematuro no final de ciclo.

TABELA 3 - Altura da parte aérea, número de folhas, diâmetro do pseudocaule e porcentagem de plantas com bulbos aos 57 dias do transplante apresentados pelas cultivares Mercedes, Bola Precoce, Crioula e Montana, provenientes de mudas M1 (128 células), M2 (200 células) e M3 (288 células). Ponta Grossa (PR). 2004.

\begin{tabular}{lcccc}
\hline \multicolumn{1}{c}{ Tratamentos } & Altura $(\mathbf{c m})$ & Número de folhas & Diâmetro $(\mathbf{m m})$ & \% de bulbificação \\
\hline Mercedes M1 & $75,11 \mathrm{a}$ & $9,07 \mathrm{abc}$ & $17,29 \mathrm{ab}$ & $89,41 \mathrm{a}$ \\
Mercedes M2 & $63,63 \mathrm{bcde}$ & $8,00 \mathrm{bc}$ & $14,42 \mathrm{bc}$ & $64,09 \mathrm{~b}$ \\
Mercedes M3 & $62,28 \mathrm{bcde}$ & $8,00 \mathrm{bc}$ & $13,07 \mathrm{c}$ & $59,33 \mathrm{~b}$ \\
Bola Precoce M1 & $72,21 \mathrm{ab}$ & $9,93 \mathrm{a}$ & $19,09 \mathrm{a}$ & $24,25 \mathrm{c}$ \\
Bola Precoce M2 & $64,79 \mathrm{abcde}$ & $9,33 \mathrm{ab}$ & $17,22 \mathrm{ab}$ & $16,32 \mathrm{~cd}$ \\
Bola Precoce M3 & $58,73 \mathrm{cde}$ & $8,67 \mathrm{abc}$ & $15,63 \mathrm{abc}$ & $10,78 \mathrm{~cd}$ \\
Crioula M1 & $69,19 \mathrm{abc}$ & $8,87 \mathrm{abc}$ & $18,33 \mathrm{a}$ & $0,00 \mathrm{~d}$ \\
Crioula M2 & $62,97 \mathrm{bcde}$ & $8,20 \mathrm{bc}$ & $15,79 \mathrm{abc}$ & $0,00 \mathrm{~d}$ \\
Crioula M3 & $56,63 \mathrm{e}$ & $7,93 \mathrm{c}$ & $14,05 \mathrm{bc}$ & $0,00 \mathrm{~d}$ \\
Montana M1 & $68,39 \mathrm{abcd}$ & $9,00 \mathrm{bc}$ & $17,36 \mathrm{ab}$ & $0,00 \mathrm{~d}$ \\
Montana M2 & $60,12 \mathrm{cde}$ & $8,60 \mathrm{abc}$ & $14,61 \mathrm{bc}$ & $0,00 \mathrm{~d}$ \\
Montana M3 & $55,45 \mathrm{de}$ & $8,13 \mathrm{bc}$ & $14,55 \mathrm{bc}$ & $0,00 \mathrm{~d}$ \\
C.V. $(\%)$ & 5,58 & 5,75 & 7,52 & 29,16 \\
\hline
\end{tabular}

*Médias seguidas da mesma letra minúscula na coluna não diferem significativamente entre si no nível de 5\% de probabilidade pelo teste de Tukey.

Ciênc. agrotec., Lavras, v. 30, n. 1, p. 58-66, jan./fev., 2006 
TABELA 4 - Porcentagem de plantas de cebola com estalo e haste floral, diâmetro do pseudocaule (mm) na colheita e após a cura dos bulbos, rendimento (t.8000 $\mathrm{m}^{-2}$ ) e massa média do bulbo (g), provenientes de mudas M1 (128 células), M2 (200 células) e M3 (288 células). Ponta Grossa (PR). 2004.

\begin{tabular}{|c|c|c|c|c|c|}
\hline Tratamentos & $\begin{array}{c}\text { Estalo } \\
(\%)\end{array}$ & $\begin{array}{c}\text { Haste floral } \\
(\%)\end{array}$ & $\begin{array}{l}\text { Diâm. pseudo- } \\
\text { caule }(\mathbf{m m})\end{array}$ & $\begin{array}{c}\text { Rend. bulbos } \\
\left(\mathbf{t . 8 0 0 0 \mathrm { m } ^ { - 2 } )}\right.\end{array}$ & $\begin{array}{c}\text { Massa média do } \\
\text { bulbo (g) }\end{array}$ \\
\hline Mercedes M1 & $83,7 \mathrm{abc}$ & $0,0 \mathrm{c}$ & 13,30 abcd & $88,85 \mathrm{ab}$ & $175,32 \mathrm{ab}$ \\
\hline Mercedes M2 & $90,8 \mathrm{ab}$ & $0,0 \mathrm{c}$ & $11,97 \mathrm{~cd}$ & 80,91 bcd & $158,06 \mathrm{bcd}$ \\
\hline Mercedes M3 & 95,4 a & $0,0 \mathrm{c}$ & $12,23 \mathrm{~cd}$ & 78,29 bcde & $154,52 \mathrm{bcd}$ \\
\hline B. Precoce M1 & $92,7 \mathrm{ab}$ & $1,8 \mathrm{bc}$ & $15,90 \mathrm{ab}$ & $85,61 \mathrm{abc}$ & $168,97 \mathrm{abc}$ \\
\hline B. Precoce M2 & $91,5 \mathrm{ab}$ & $0,0 \mathrm{c}$ & $12,77 \mathrm{abcd}$ & 78,70 bcde & $155,32 \mathrm{bcd}$ \\
\hline B. Precoce M3 & 99,6 a & $0,0 \mathrm{c}$ & $11,33 \mathrm{~d}$ & $61,67 \mathrm{f}$ & $120,45 \mathrm{e}$ \\
\hline Crioula M1 & $69,1 \mathrm{c}$ & 14,9 a & $15,93 \mathrm{a}$ & $85,12 \mathrm{abc}$ & $168,06 \mathrm{abc}$ \\
\hline Crioula M2 & $90,8 \mathrm{ab}$ & $4,4 \mathrm{bc}$ & $12,67 \mathrm{bcd}$ & $86,29 \mathrm{abc}$ & $168,54 \mathrm{abc}$ \\
\hline Crioula M3 & $88,4 \mathrm{ab}$ & $6,6 \mathrm{~b}$ & $13,23 \mathrm{abcd}$ & 70,34 def & $140,28 \mathrm{de}$ \\
\hline Montana M1 & $76,9 \mathrm{bc}$ & $7,9 \mathrm{~b}$ & $15,87 \mathrm{ab}$ & 93,92 a & 185,55 a \\
\hline Montana M2 & $83,4 \mathrm{abc}$ & $6,2 \mathrm{bc}$ & $14,50 \mathrm{abcd}$ & 73,39 cdef & 144,85 cde \\
\hline Montana M3 & $84,5 \mathrm{abc}$ & $5,7 \mathrm{bc}$ & $14,80 \mathrm{abc}$ & 67,63 ef & $133,57 \mathrm{de}$ \\
\hline C.V. $(\%)$ & 6,68 & 54,43 & 8,00 & 5,57 & 5,50 \\
\hline
\end{tabular}

*Médias seguidas da mesma letra minúscula na coluna não diferem significativamente entre si no nível de $5 \%$ de probabilidade pelo teste de Tukey.

O ciclo total, da semeadura à colheita apresentado por Mercedes foi de 143 dias, Bola Precoce, de 154 dias e Crioula e Montana, de 165 dias. A precocidade foi em torno de 15 dias para as cultivares, exceto para Mercedes, considerando que esta possui ciclo de 140 a 150 dias (COSTA et al., 2002), Bola Precoce, de 170 a 190 dias e Crioula, de 180 a 200 dias (GANDIN et al., 2001).

A ocorrência de florescimento prematuro no final de ciclo definiu a colheita de algumas cultivares como Crioula e Montana, principalmente nos tratamentos M1 (Tabela 4). Nesta condição, a planta emite haste floral antes da completa maturação dos bulbos e dificulta a maturação. Conforme Jones \& Mann (1963), a medida que se aumenta o diâmetro das mudas, a massa média dos bulbos e a produção total crescem até certo ponto, porém a porcentagem de florescimento prematuro também aumenta, o que pode justificar o maior percentual em M1. Entre cultivares, observou-se que Mercedes não apresentou essa ocorrência em nenhum dos tipos de mudas, o que é uma característica vantajosa.

Nessa região, o florescimento prematuro é temido durante a produção de bulbos, porque o início da bulbificação coincide na primavera quando freqüentemente se registra ocorrência de frentes frias, tendo-se temperaturas baixas que induzem a planta ao florescimento prematuro.

Os maiores diâmetros do pseudocaule acompanharam o comportamento observado tanto na altura como no número de folhas, em que os maiores valores foram encontrados nos tratamentos M1 e os menores em M3, nem sempre com diferença significativa (Tabela 4). Confirma o comportamento observado para ocorrência de estalo, com melhor maturação para tratamentos M3. Dos 57 dias do transplante até a colheita, o diâmetro diminuiu sensivelmente de $15,95 \mathrm{~mm}$ para $13,70 \mathrm{~mm}$, considerandose favorável para a maturação dos bulbos.

O cultivo na presença de palhada assegurou vantagens quanto ao manejo da cultura, como o menor número de irrigações efetuados (8), quando no cultivo convencional normalmente é realizado mais que 20 irrigações durante o ciclo. Observou-se que, a partir de setembro, a ocorrência de precipitações e a presença de cobertura do solo reduziram muito o uso de irrigação. Nas regiões de Irati e Imbituva (PR), é significativo o número 
de produtores que fazem o cultivo na palhada na tentativa de diminuir o custo da irrigação. Outra vantagem direta da presença da palhada foi a manutenção da cultura no limpo durante quase todo o ciclo.

As características do desenvolvimento vegetativo observados na altura, número de folhas, diâmetro do pseudocaule, resultaram no final do cultivo, em valores altamente expressivos no rendimento de bulbos (Tabela 4).

A produtividade média obtida de $79,23 \mathrm{t} .8000 \mathrm{~m}^{-2}$ comparada à média brasileira de 17,00 t.ha-1 (COSTA et al., 2002) e à média do Estado, de 10,7 t.ha ${ }^{-1}$ (RESENDE et al., 2002), demonstra o quanto pode-se ter de avanço em produtividade. Embora a produção de mudas em bandejas seja mais onerosa que o método convencional, as vantagens múltiplas tanto do maior rendimento e da melhor qualidade obtidos demonstram que é necessário incorporar novas técnicas e que a tecnologia pode ser recomendada num mercado competitivo. Aliado a isso, faz-se necessário pesquisas para diminuir o custo de produção de mudas em bandejas, como o uso de substratos alternativos e maior número de plântulas por célula. Quanto aos tratamentos mais produtivos foram Montana M1, Mercedes M1, Bola Precoce M1, Crioula M1 e M2; no entanto, diferiram significativamente apenas de Bola Precoce M3 e Montana M3. Entre os tratamentos, praticamente não ocorreram diferenças entre M1 e M2; quando houveram, foram entre M1 e M3 (Tabelas 1, 2, 3, 4 e 5).

Na Coréia, Lee et al. (2000), observaram que em volumes maiores de células (bandejas de 72 e 128), maior foi o tamanho da muda e a produção de bulbos, de $125 \mathrm{t} /$ ha e $120 \mathrm{t} / \mathrm{ha}$, respectivamente. Na Flórida, as mudas produzidas em volume de célula de $4,0 \mathrm{~cm}^{3}$ produziram $16 \%$ a menos de bulbos de maior padrão do que mudas oriundas de volume de $7,1 \mathrm{~cm}^{3}$ (LESKOVAR \& VAVRINA, 1999). No entanto, Maluf et al. (2003), comparando a produção de mudas em bandejas e em canteiros, não observaram diferença no rendimento de bulbos, de 81852 $\mathrm{kg} /$ ha para o primeiro método e de $82920 \mathrm{~kg} / \mathrm{ha}$ para o segundo, embora não haja informação se a produção de mudas foi realizada em cultivo protegido. Ferreira (2000) relatou que alguns produtores brasileiros têm usado bandejas de poliestireno expandido com 288 células e três plântulas por célula.

TABELA 5 - Classificação dos bulbos de cebola em porcentagem nas classes 2 (>35<50 mm), 3 (>50<60 mm), 3C (>60 $<70 \mathrm{~mm})$, e 4 (>70<90 mm) das cultivares Mercedes, Bola Precoce, Crioula e Montana provenientes de mudas M1 (128 células), M2 (200 células) e M3 (288 células). Ponta Grossa (PR). 2004

\begin{tabular}{lcccc}
\hline \multirow{2}{*}{ Tratamentos } & \multicolumn{5}{c}{ Porcentagem de bulbos nas classes } \\
\cline { 2 - 5 } & $\mathbf{2}$ & $\mathbf{3}$ & $\mathbf{3 C}$ & $\mathbf{4}$ \\
\hline Mercedes M1 & $0,00 \mathrm{~b}$ & $18,95 \mathrm{~b}$ & $42,14 \mathrm{~cd}$ & $38,91 \mathrm{ab}$ \\
Mercedes M2 & $0,00 \mathrm{~b}$ & $20,83 \mathrm{~b}$ & $39,58 \mathrm{~cd}$ & $39,58 \mathrm{ab}$ \\
Mercedes M3 & $8,43 \mathrm{a}$ & $27,39 \mathrm{~b}$ & $27,39 \mathrm{~d}$ & $35,75 \mathrm{ab}$ \\
B. Precoce M1 & $0,00 \mathrm{~b}$ & $3,19 \mathrm{~b}$ & $57,90 \mathrm{abc}$ & $38,91 \mathrm{ab}$ \\
B. Precoce M2 & $0,00 \mathrm{~b}$ & $7,29 \mathrm{~b}$ & $73,72 \mathrm{a}$ & $18,99 \mathrm{bc}$ \\
B. Precoce M3 & $0,00 \mathrm{~b}$ & $59,38 \mathrm{a}$ & $40,63 \mathrm{~cd}$ & $0,00 \mathrm{c}$ \\
Crioula M1 & $0,00 \mathrm{~b}$ & $3,16 \mathrm{~b}$ & $48,45 \mathrm{abcd}$ & $48,39 \mathrm{a}$ \\
Crioula M2 & $0,00 \mathrm{~b}$ & $6,25 \mathrm{~b}$ & $57,29 \mathrm{abc}$ & $36,46 \mathrm{ab}$ \\
Crioula M3 & $0,00 \mathrm{~b}$ & $21,40 \mathrm{~b}$ & $59,51 \mathrm{abc}$ & $19,09 \mathrm{bc}$ \\
Montana M1 & $0,00 \mathrm{~b}$ & $6,25 \mathrm{~b}$ & $44,19 \mathrm{bcd}$ & $50,60 \mathrm{a}$ \\
Montana M2 & $0,00 \mathrm{~b}$ & $15,79 \mathrm{~b}$ & $53,63 \mathrm{abcd}$ & $30,58 \mathrm{ab}$ \\
Montana M3 & $0,00 \mathrm{~b}$ & $24,19 \mathrm{~b}$ & $70,46 \mathrm{ab}$ & $5,34 \mathrm{c}$ \\
C.V. \% & 78,00 & 51,39 & 18,19 & 23,84 \\
\hline
\end{tabular}

${ }^{*}$ Médias seguidas da mesma letra minúscula na coluna não diferem significativamente entre si no nível de $5 \%$ de probabilidade pelo teste de Tukey.

Ciênc. agrotec., Lavras, v. 30, n. 1, p. 58-66, jan./fev., 2006 
Diferentes tamanhos de bandejas proporcionarão mudas com diferentes tamanhos aptas para serem transplantadas. O tamanho das mudas influenciará a produção e, mais especificamente a qualidade dos bulbos de cebola. A massa média dos bulbos de 156,12 g (Tabela 4), demonstra a alta qualidade das mudas M1, M2 e M3. Quanto maior o tamanho da muda usado, maior foi a massa média do bulbo, embora as maiores diferenças se encontrem entre M1 e M3, exceto em Crioula M1 e M2 que apresentaram valores de pesos médios semelhantes e ambos diferiram de M3.

A maior evidência da alta qualidade do produto foi observada após a classificação dos bulbos em classes (Tabela 5). Cabe destacar que não houve bulbos da classe 1 (menor que $35 \mathrm{~mm}$ ), não comerciais, tampouco da classe 2, exceto Mercedes M3 com 8,43\%. Na classe 3, Bola Precoce M3 apresentou o maior percentual (59,38\%), diferindo significativamente dos demais tratamentos. Dependendo do mercado a ser comercializado, poderá ser usado especificamente esse tipo de muda.

A maior concentração da produção foi observada na classe 3C, destacando-se Bola Precoce M2 e Montana M3. No entanto, essas diferiram significativamente apenas de Mercedes M1, M2, M3 e Bola Precoce M3. Já, na classe 4, coube o destaque para Montana M1 e Crioula M1, as quais diferiram significativamente de Bola Precoce M2 e M3, Crioula M3 e Montana M3, pois os tratamentos M3 produziram menor percentual de bulbos dessa classe.

Se considerarmos que a preferência do mercado consumidor nacional é por bulbos das classes 3C e 4 (SILVA et al., 1991), somando os percentuais das duas classes, destacam-se os tratamentos Mercedes M1, M2, Bola Precoce M1 e M2, Crioula M1, M2 e M3 e Montana M1, M2 e M3, com percentuais acima de $75 \%$ nessas classes. Esses resultados são de grande interesse do produtor, pois a partir daí, tem-se a definição do preço. Ficaram excluídos desse percentual, somente Mercedes M3 (63,14\%) e Bola Precoce M3 (40,63\%).

\section{CONCLUSÕES}

a) A melhor qualidade de mudas foi obtida na bandeja de 128 células para todas as cultivares (Mercedes, Bola Precoce, Crioula e Montana).

b) As mudas provenientes de bandejas promoveram expressivo desenvolvimento vegetativo e alto rendimento (79,23 t.8000 $\left.\mathrm{m}^{-2}\right)$, tendo as cultivares Mercedes e Bola Precoce (com mudas provenientes das bandejas de 128 e 200 células) e Crioula e Montana (com mudas provenientes das bandejas de 128, 200 e 288 células), apresentado percentuais acima de $75 \%$ de bulbos nas classes $3 \mathrm{C}$ e 4 .

\section{REFERÊNCIAS BIBLIOGRÁFICAS}

AMADO, T. J. C.; MATOS, A. T.; TORRES, L. Flutuação da temperatura e umidade do solo sob preparo convencional e em faixas na cultura da cebola. Pesquisa Agropecuária Brasileira, Brasília, v. 25, n. 4, p. 625-631, 1990.

BARROS, S. B. M. de. Avaliação de diferentes recipientes na produção de mudas de tomate (Lycopersicon esculentum Mill) e pepino(Cucumis sativus L.). 1997. $70 \mathrm{f}$. Dissertação (Mestrado) - Escola Superior de Agricultura de Luiz de Queiroz, Piracicaba, 1997.

BOEING, G. Fatores que afetam a qualidade da cebola na agricultura familiar catarinense. Florianópolis: Instituto CEPA/SC, 2002. 80 p.

BREWSTER, J. L. Onions and other vegetables alliums. Wallingford: CAB International, 1994. 236 p.

CARDOSO, A. I. I.; COSTA, C. P. Production of onion bulb sets in styrofoam trays. Scientia Agricola, Piracicaba, v. 56, n. 4, p. 969-974, 1999.

COSTA, N. D.; LEITE, D. L.; SANTOS, C. A. F.; CANDEIA, J. A.; VIDIGAL, S. M. Cultivares de cebola. Informe Agropecuário, Belo Horizonte, v. 23, n. 218, p. 20-27, 2002.

DELLACECCA, V.; LOVATO, A. F. S.; STOFFELLA, P. J.; CANTLIFFE, D. J.; DAMATO, G. Effects of different plant densities and planting systems on onion (Allium cepa $\mathrm{L}$.) bulb quality and yield. Acta Horticulturae, The Hague, n. 533, p. 197-203, 2000.

EPAGRI. Pesquisa testa novas técnicas para produção de mudas de cebola. Agropecuária Catarinense, Florianópolis, v. 8, n. 1, p. 25-28, 1995.

FERREIRA, M. D. Cultura da cebola: recomendações técnicas. Campinas: ASGROW, 2000. 36 p.

FONTES, P. C. R.; SILVA, D. J. H. Métodos de produção de cebola. Informe Agropecuário, Belo Horizonte, v. 23, n. 218, p. 28-35, 2002.

GANDIN, C. L.; GUIMARÃES, D. R.; THOMAZELLI, L. F.; BOEING, G. Escolha da cultivar adequada para produção de cebola. Agropecuária Catarinense, Florianópolis, v. 14, n. 2, p. 45-48, 2001. 
JAIME, M.; ROBERTS, L.; MCDONALD, M. R. Growing onion transplants in plug trays: Ministry of Agriculture and Food. 2001. Disponível em: <http://www.gov.on.ca/OMMĀF/ 'english/crops/facts/01-019.htm >. Acesso em: 7 out. 2004.

JONES, H. A.; MANN, L. K. Onions and their allies: botany, cultivation and utilization. London: Leonard Hill, 1963. $286 \mathrm{p}$.

LATIMER, J. G. Container size and shape influence growth and landscape performance of marigold seedling. HortScience, Alexandria, v. 26, p. 124-126, 1991.

LEE, J. S.; SEONG, K. C.; SIN, Y. A.; RO, H. M.; UM, Y. C. Introduction of spring cultivation of onions by adapting the plug seedling system in the middle region of Korean peninsula. Korean Journal of Horticultural Science and Technology, Korea, v. 18, n. 1, p. 9-13, 2000.

LESKOVAR, D. I.; VAVRINA, C. S. Onion growth and yield are infuenced by transplant tray cell size and age. Scientia Horticulturae, Amsterdam, v. 80, n. 3-4, p. 133-143, 1999.

MALUF, L. E. J.; SCHMIDT, P. A.; MADEIRA, N. R.; SOUSA, R. J. de; LEITE, G. M. V.; OKADA, A.; SANTOS, F. H. V. Avaliação do sistema de produção de mudas de mudas de cebola em bandejas. Horticultura Brasileira, Brasília, v. 21, n. 2, 2003. Suplemento. CD-ROM.

MINAMI, K. Produção de mudas de alta qualidade em Horticultura. São Paulo: Agronômica Ceres, 1995. 357 p.

MODOLO, V. A.; TESSARIOLI NETO, J. Avaliação do desenvolvimento de mudas de quiabeiro (Abelmoschus esculentus (L.) Moench) em diferentes tipos de bandejas e substrato. In: CONGRESSO BRASILEIRO DE OLERICULTURA, 1998, Petrolina, PE. Anais... Petrolina: [s.n.], 1998. CD-ROM.

REGHIN, M. Y.; OTTO, R. F.; VINNE, J. van der. Efeito da densidade de mudas por célula e do volume da célula na produção de mudas e cultivo da rúcula. Ciência e Agrotecnologia, Lavras, v. 28, n. 2, p. 289-297, 2004.

RESENDE, G. M. de; YURI, J. E.; MOTA, J. R.; SOUZA, R. de; FREITAS, S. A. C. de; RODRIGUES JUNIOR, J. C. Efeitos de tipos de bandejas e idade de transplantio de mudas sobre o desenvolvimento e produtividade da alface americana. Horticultura Brasileira, Brasília, v. 21, n. 3, p. 558-562, 2003.

RESENDE, L. M. A.; MASCARENHAS, M. H. T.; SIMÃO, M. L. R. Panorama da produção e da comercialização da cebola em Minas Gerais. Informe Agropecuário, Belo Horizonte, v. 23, n. 218, p. 7-19, 2002.

SEAB/DERAL. Valor bruto da agropecuária paranaense. 2002. Disponível em: Łhttp:/www.pr.govbr/seab/deral Acesso em: 3 out. 2004.

SILVA, E.; TEIXEIRA, L. A. J.; AMADO, T. J. C. The increase in onion production in Santa Catarina State, South, Brasil. Onion Newsletter for the Tropics, [S.1.], n. 3, p. 7-9, 1991.

VINCENZO, M. C. V. de; TESSARIOLI NETO, J. Onion seedling production in styrofoam trays under controlled environment, as summer-planted onions. Scientia Agricola, Piracicaba, v. 60, n. 1, p. 65-69, 2003. 